\title{
An improved partially interleaved transformer structure for high-voltage high- frequency multiple-output applications
}

Zhao, Bin; Ouyang, Ziwei; Andersen, Michael A. E.; Duffy, Maeve; Hurley, W. G.

Published in:

I E E E Transactions on Industrial Electronics

Link to article, DOI:

10.1109/TIE.2018.2840499

Publication date:

2018

Document Version

Peer reviewed version

Link back to DTU Orbit

Citation (APA):

Zhao, B., Ouyang, Z., Andersen, M. A. E., Duffy, M., \& Hurley, W. G. (2018). An improved partially interleaved transformer structure for high-voltage high-frequency multiple-output applications. I E E E Transactions on Industrial Electronics, 66(4), 2691-2702. https://doi.org/10.1109/TIE.2018.2840499

\section{General rights}

Copyright and moral rights for the publications made accessible in the public portal are retained by the authors and/or other copyright owners and it is a condition of accessing publications that users recognise and abide by the legal requirements associated with these rights.

- Users may download and print one copy of any publication from the public portal for the purpose of private study or research.

- You may not further distribute the material or use it for any profit-making activity or commercial gain

- You may freely distribute the URL identifying the publication in the public portal 


\title{
An Improved Partially Interleaved Transformer Structure for High-voltage High-frequency Multiple-output Applications
}

\author{
Bin Zhao*, Member, IEEE, Ziwei Ouyang, Senior Member, IEEE, Maeve Duffy, Senior \\ Member, IEEE, Michael A. E. Andersen, Senior Member, IEEE and Gerard Hurley, Fellow, \\ IEEE
}

\begin{abstract}
This paper proposes an improved partially interleaved structure for high-voltage (several kV) high-frequency (several hundred kHz) multiple-output applications. The proposed transformer structure is compared with other typical structures with the leakage inductance, $A C$ capacitance, $A C$ resistance and the ratio of $A C / D C$ resistance taken into consideration. The proposed structure features lower leakage inductance, smaller AC capacitance, lower AC resistance and lower ratio of AC-DC resistance, which is suitable for high-frequency high-efficiency applications. A planar transformer with the proposed structure was built and tested in an LCLC resonant converter, where the input voltage is $40 \mathrm{~V}$, output is $4800 \mathrm{~V}$, switching frequency is $500 \mathrm{kHz}$, the output power is $288 \mathrm{~W}$ and the efficiency is $\mathbf{9 6 . 8 \%}$, which validates the analysis.
\end{abstract}

Index Terms - high-voltage, high-frequency, improved partially interleaved structure, multiple-output, planar transformer

\section{INTRODUCTION}

$\mathrm{H}$ IGH-voltage power supplies with multiple outputs are widely used in Travelling-Wave Tube Amplifiers [1] (TWTAs), lasers [2], Magnetic Resonance Imaging (MRI) [3], where several high-voltage outputs are required by the system. Nowadays, the power supplies are moving towards high power density and high efficiency, which is mainly restricted by the magnetic components and semiconductors in high-voltage multiple-output application. The emergence of novel power switches, such as $\mathrm{GaN}$ and $\mathrm{SiC}$ devices $[4,5,6]$ helps to increase the power density and efficiency from the semiconductor aspect. However, the magnetic design, especially the high-voltage transformer design is still a big challenge. The reason can be given as follows. In order to achieve high efficiency, resonant topologies are applied to

Manuscript received Dec 22, 2017; revised Feb 11, Mar 20, 2018; accepted May 6, 2018.

Bin Zhao, Ziwei Ouyang and Michael A. E. Andersen are with Department of Electrical Engineering, Technical University of Denmark, Kgs. Lyngby, Denmark. (e-mail: binzhao@elektro.dtu.dk).

Maeve Duffy and Gerard Hurley are with Power Electronics Research Center, National University of Ireland, Galway, Ireland.

Gerard Hurley is also with School of Electrical and Electronic Engineering, Tianjin University of Technology, Tianjin, China. reduce the switching loss. The structure of a high-voltage planar transformer has a crucial role on the performance of a resonant converter since its parasitic impedances are utilized to form a resonant tank $[7,8,9]$. As for the leakage inductance, the general way to reduce the leakage is using the interleaving structure. However, the parasitic capacitance will increase as the interleaving will lead to more overlapped area. From the aspect of the parasitic capacitance, the common way is to shift the winding to reduce the overlapped area. However, the shifting will result in the increase of the leakage. As a result, the leakage inductance and parasitic capacitance are interrelated and need careful consideration. Taking the LCLC resonant converter as an example (Fig. 1a), the leakage inductance $\left(\mathrm{L}_{\mathrm{r}}\right)$, magnetizing inductance $\left(\mathrm{L}_{\mathrm{m}}\right)$ and parasitic capacitance $\left(\mathrm{C}_{\mathrm{p}}\right)$ of the transformer are utilized in the resonant tank. The $3 \mathrm{D}$ structure of a high-voltage planar transformer is shown in Fig. 1b. As for the switching frequency of the LCLC resonant converter, it is lower than $100 \mathrm{kHz}$, which is mainly limited by the parasitic parameters of the high-voltage transformer [1].

The planar transformer has been investigated and used comprehensively since it was proposed. Previous research investigated different winding configurations [10, 11], the analysis of impedances [12] and the design of the planar transformers [13, 14]. However, these researches mainly focused on low-voltage high-current applications, which is due to the difficulty in designing the adequate electrical insulation. However, with the development of the Polyimide PCB, the capability for providing electrical insulation has improved greatly, with the electric field intensity increasing from 3 $\mathrm{kV} / \mathrm{mm}$ to $80 \mathrm{kV} / \mathrm{mm}$ or higher [15], which contributes to the application of the planar transformer in the high-voltage field.

In high-voltage applications, apart from the $\mathrm{AC} / \mathrm{DC}$ resistance and $L_{r}$, the electrical insulation and $C_{p}$ need further investigation [14]. However, $C_{p}$ is always ignored in the previous researches, such as LLC resonant converters. This is due to the larger impedance of $C_{p}$ compared with that of $\mathrm{L}_{\mathrm{m}}$. However, in high-voltage applications, in order to boost the output voltage, there are few turns in the primary side with a large number of turns in the secondary side. As a result, a large $\mathrm{C}_{\mathrm{p}}$ exists, the impedance of which is comparable with that of $\mathrm{L}_{\mathrm{m}}$. Therefore, $\mathrm{C}_{\mathrm{p}}$ cannot be ignored.

In resonant converters, $\mathrm{C}_{\mathrm{p}}$ is utilized as the resonant component, which will affect the efficiency and switching 


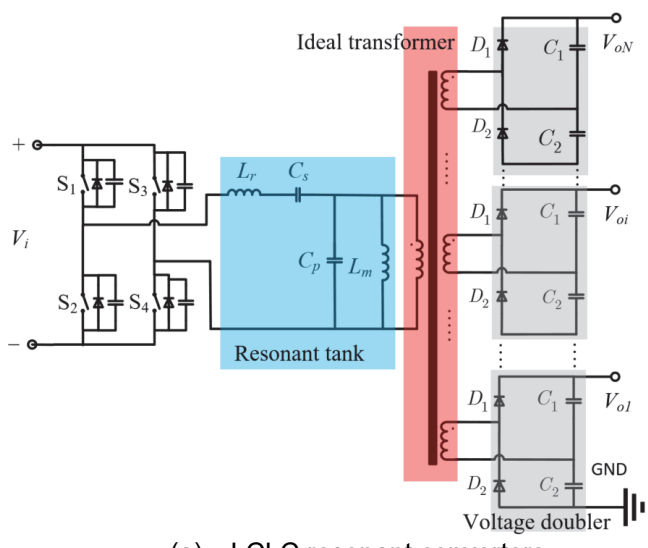

(a) LCLC resonant converters

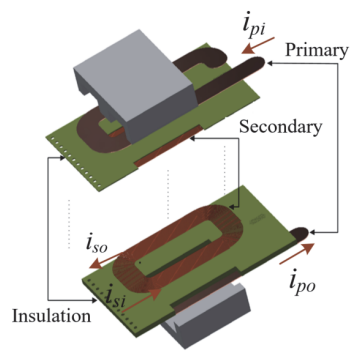

(b) 3D structure of a high-voltage planar transformer

Fig. 1 High voltage transformer with voltage doublers

frequency of the converter. Take the LCLC resonant converter as an example [16], the energy to charge or discharge $C_{p}$ is mainly provided by $\mathrm{L}_{\mathrm{m}}$. With higher $\mathrm{C}_{\mathrm{p}}$, the energy required for the charging or discharging will increase, which will increase the conduction loss. In this way, $\mathrm{C}_{\mathrm{p}}$ needs careful design.

This paper focuses on the applications of the planar transform in high-voltage field and manages to do the trade-off design among all the parasitics. An improved partially interleaved transformer structure for high-voltage high-frequency multiple-output applications is proposed. The proposed structure and other typical structures are shown in Section II. In Section III, IV and V, the comparison between the proposed structure and other typical structures is made, with $\mathrm{L}_{\mathrm{r}}$, $A C$ resistance $\left(R_{a c}\right)$, the ratio of $A C / D C$ resistance and $A C$ capacitance $\left(C_{p}\right)$ taken into consideration. In Section VI, the partial discharge of the high-voltage transformer caused by the partial interleaving is discussed. In Section VII, a planar transformer with the proposed structure is built and tested in LCLC resonant converters. Section VIII provides a summary of the whole paper.

\section{WINDING CONFIGURATIONS FOR HIGH-VOLTAGE PLANAR TRANSFORMERS}

In high-voltage multiple-output DC-DC converters, as illustrated in Fig. 1, there are always several secondary windings and to further boost the voltage, each secondary winding is often connected to a voltage doubler. Each output of a voltage doubler can be used as an independent output. As a result, there are several outputs.

Interleaving is a general method to reduce the leakage inductance; however, it may cause an increase of the parasitic capacitance. In this paper, the overall effect of interleaving is investigated. As for the secondary winding, each secondary winding needs at least two layers, with one layer for the incoming line and the other for the outgoing line. The configurations of secondary windings considered in this work are illustrated in Fig. 2. The parasitic capacitance between two adjacent turns $\left(\mathrm{C}_{\text {inter }}\right)$ and between two layers $\left(\mathrm{C}_{\text {intra }}\right)$ are labeled.

The single-layer structure is shown in Fig. 2(a), where all the turns in a secondary winding are in a single layer, while the other layer is only used for the outgoing line. As a result, $\mathrm{C}_{\text {intra }}$ is low. However, it is obvious that the layer for the outgoing line is not fully utilized, which results in higher DC resistance.

The two-layer structure is shown in Fig. 2(b). In this structure, half of the turns in a secondary winding are on one layer while other turns are on the other layer. The two layers are fully utilized and the conductors have the largest width compared with the single-layer structure and the non-interleaved structure, which means that the lowest DC resistance can be achieved. However, because of the large overlapped area, the parasitic capacitance may be high.

The non-overlapped structure is shown in Fig. 2(c). In this structure, half of the turns are on one layer while other turns are on the other layer, which is similar to the two-layer structure. Compared with the two-layer structure, the overlapped area of the turns is minimized to reduce the intra-winding parasitic capacitance.

Combing the primary windings with the secondary windings, a range of winding configurations of the planar transformer is derived, as shown in Fig. 3. There is one primary winding with $m$ turns and $n$ secondary windings. Fig. 3(a), (c) and (e) show the non-interleaved structures, while Fig. 3(b), (d) and (f) show the partially interleaved structures. In order to ensure the effectiveness of the electrical insulation, a thick insulation is used between the high voltage sides of the primary and secondary windings in the partially interleaved structures. The thickness of this insulation is determined by the insulation material and the voltage between the primary and secondary windings. In addition, the distribution of the parasitic capacitance is also shown in Fig. 3, which will be discussed in Section V.

The derivation of the equations, such as the leakage inductance and $\mathrm{AC}$ capacitance, are based on the general structure shown in Fig. 3 and can be easily adopted to other cases easily. In addition, an example is also given to validate the analysis. In order to make a fair comparison, in this example, all the six winding structures use the same magnetic core, which is FEE 38/16/25 and the magnetic material is N87 from

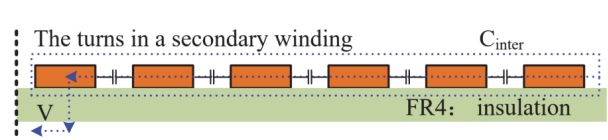

(a) Single-layer structure

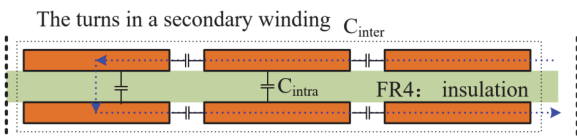

(b) Two-layer structure

Fig. 2 Configurations of the secondary winding

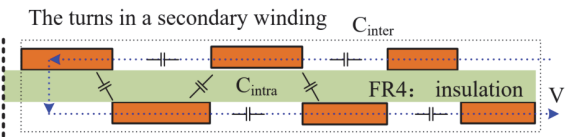

(c) Non-overlapped structure 


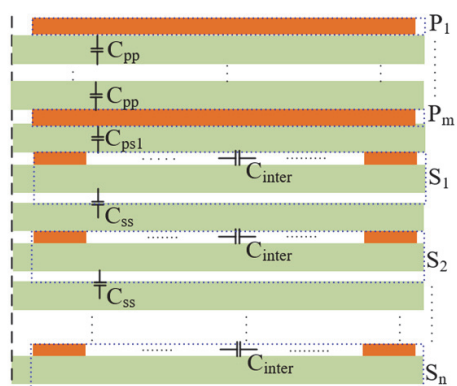

(a) $\mathrm{W}_{1}$ (Non-interleaved, single layer)

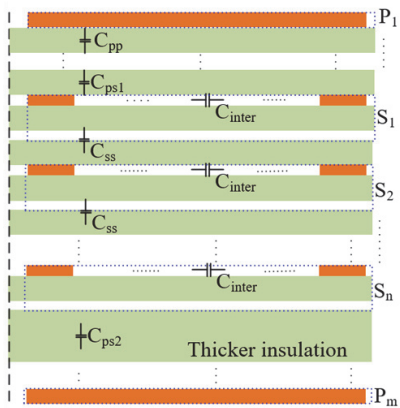

(b) $\mathrm{W}_{2}$ (Partially interleaved, single layer)

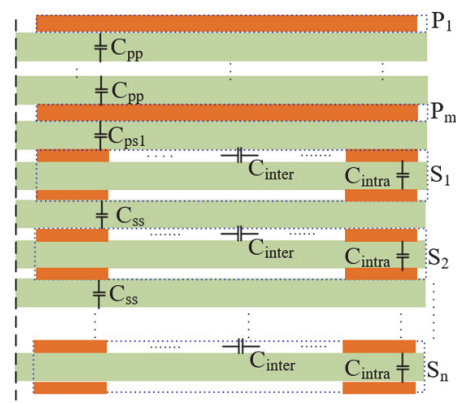

(c) $\mathrm{W}_{3}$ (Non-interleaved, two-layer)

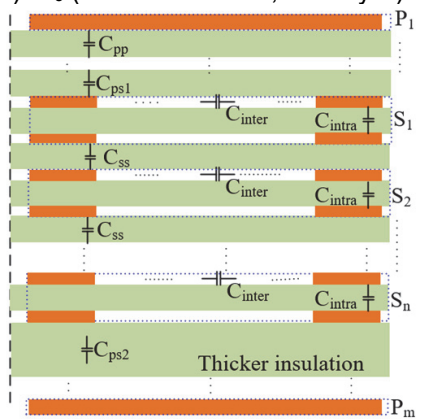

(d) $\mathrm{W}_{4}$ (Partially-interleaved, two-layer)

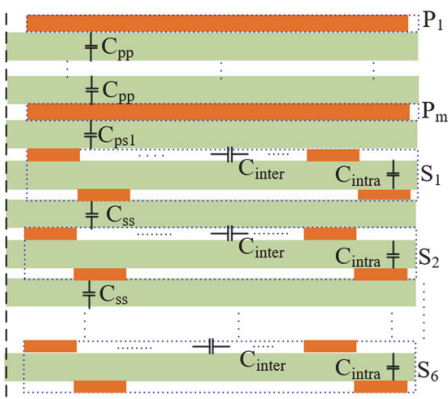

(e) $W_{5}$ (Non-interleaved, non-overlapped)

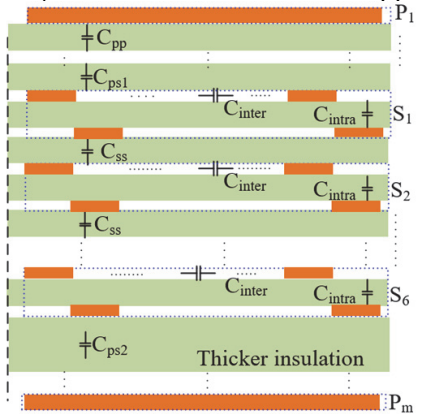

(f) $\mathrm{W}_{6}$ (Partially-interleaved, non-overlapped)

Fig. 3 Overview of the winding configurations for high-voltage planar transformers

TDK. In addition, each structure has one primary winding and six secondary windings, with two turns in the primary winding and twenty turns in each secondary winding. The parameters of the windings are given in Table I.

In the following parts, the parasitic parameters of the winding configurations $\left(L_{r}\right.$, the ratio of AC/DC resistance, $R_{a c}$ and $\mathrm{C}_{\mathrm{p}}$ ) will be compared.

\section{LEAKAGE INDUCTANCE}

In a resonant converter, $\mathrm{L}_{\mathrm{r}}$ is always used as a resonant component in the resonant tank and will affect the resonant condition. As a result, it is important to predict $\mathrm{L}_{\mathrm{r}}$. In Part A, the $\mathrm{L}_{\mathrm{r}}$ of each winding configuration is calculated based on the Magneto-motive Force (MMF). In Part $\mathrm{B}$, the $\mathrm{L}_{r}$ is simulated in Ansys Maxwell. Finally, the calculated results are compared with the simulated results to validate the correctness of the calculations.

TABLE I

PARAMETERS OF HIGH VOLTAGE PLANAR TRANSFORMERS

\begin{tabular}{ccc}
\hline \hline Symbol & Quantity & Value \\
$w_{p}$ & Width of the primary winding & $7.27 \mathrm{~mm}$ \\
$d_{p}$ & Thickness of the primary winding & $0.2 \mathrm{~mm}$ \\
$d_{s}$ & Thickness of the secondary winding & $70 \mu \mathrm{m}$ \\
$d_{n i}$ & Thickness of the normal insulation & $0.3 \mathrm{~mm}$ \\
$d_{t i}$ & Thickness of the thicker insulation & $1.6 \mathrm{~mm}$ \\
$d_{c w}$ & The safe distance between the & $1.7 \mathrm{~mm}$ \\
$d_{s 1}$ & Thindings and the core & $0.27 \mathrm{~mm}$ \\
$d_{s 2}$ & $\begin{array}{c}\text { The width of the turns in single-layer } \\
\text { structure }\end{array}$ & $0.64 \mathrm{~mm}$ \\
$d_{s 3}$ & $\begin{array}{c}\text { The width of the turns in } \\
\text { non-overlapped structure }\end{array}$ & $0.36 \mathrm{~mm}$ \\
$P_{T}$ & Nominal power of the transformer & $288 \mathrm{~W}$ \\
\hline \hline
\end{tabular}

\section{A. Calculations of leakage inductance}

The calculation of $\mathrm{L}_{\mathrm{r}}$ is based on the MMF distribution. The magnetizing current is ignored and the ampere-turn of the primary windings is equal to that of the secondary windings. Assuming $i_{p}$ is applied to the primary winding, the MMF distribution is shown in Fig. 4. It can be seen from Fig. 4 that compared with the corresponding non-interleaved structure, the highest magnetic field intensity is reduced with partially interleaved structures, which means the even distribution of the magnetic field.

Assuming the magnetic field intensity is constant in the horizontal direction, based on the distributions of MMF, $H$ can be calculated by

$$
\sum_{i=1}^{N} I_{i}=H W_{w}
$$

where $W_{w}$ is the width of the core widow. $\sum_{i=1}^{N} I_{i}$ is the total current that contributes to MMF. Calculations are carried out by assuming the direction out of the paper is positive while the direction into the paper is negative.

As a result, the magnetic energy, $E_{m}$ can be derived by the integration of the magnetic energy density over the core window volume

$$
E_{m}=\frac{1}{2} \iiint \mu_{0} \mu_{r} H^{2} d V
$$

According to the relation of the transformer leakage inductance, $L_{r}$ and the magnetic energy

$$
E_{m}=\frac{1}{2} L_{r} i_{p}^{2}
$$

Combing (2) and (3), the $\mathrm{L}_{\mathrm{r}}$ referred to the primary side can be calculated by 


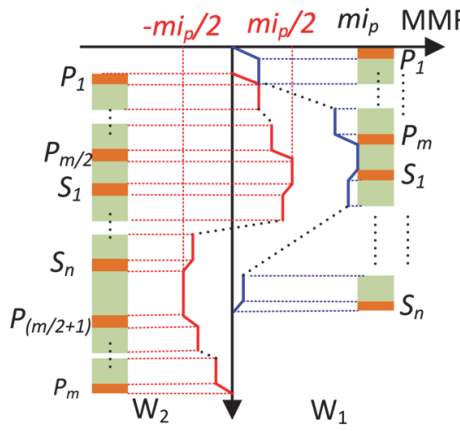

(a) Distribution of MMF of $\mathrm{W}_{1}$ and $\mathrm{W}_{2}$

$$
L_{r}=\frac{1}{i_{p}^{2}} \iiint \mu_{0} \mu_{r} H^{2} d V
$$

Fig. 4 Distribution of MMF in different configurations

where $i_{p}$ is the current excitation applied to the primary winding. It should be pointed out that (4) is only valid considering a linear operation point, far from magnetic saturation.

The winding configurations with the parameters in Table I are used as an example to compared the leakage inductance. The calculation results of $\mathrm{L}_{\mathrm{r}}$ are listed in Table II. It may be concluded that with the partially interleaved structures $\left(\mathrm{W}_{2}, \mathrm{~W}_{4}\right.$ and $\mathrm{W}_{6}$ ), compared with the corresponding non-interleaved structures $\left(\mathrm{W}_{1}, \mathrm{~W}_{3}\right.$ and $\left.\mathrm{W}_{5}\right)$, the $\mathrm{L}_{\mathrm{r}}$ is reduced by half.

TABLE II

CALCULATION RESULTS OF THE LEAKAGE INDUCTANCES

\begin{tabular}{cc}
\hline \hline Winding configurations & Value $(\mathrm{nH})$ \\
$\mathrm{W}_{1}$ & 125.02 \\
$\mathrm{~W}_{2}$ & 54.54 \\
$\mathrm{~W}_{3}, \mathrm{~W}_{5}$ & 137.78 \\
$\mathrm{~W}_{4}, \quad \mathrm{~W}_{6}$ & 60.37 \\
\hline \hline
\end{tabular}

It should be pointed out that the analytical calculations are based on the assumption that the current is distributed evenly through the conductors. However, in the range of several hundred $\mathrm{kHz}$, the relative errors are acceptable [17].

\section{B. Simulation of leakage inductance}

In order to validate the accuracy of the calculation results, Finite Element Analysis (FEA) simulations were carried out in Ansys Maxwell with the same current levels applied to the primary and secondary windings as in calculations. The distributions of the magnetic field intensity, $H$, in $\mathrm{W}_{1}, \mathrm{~W}_{2}$ and $\mathrm{W}_{4}$ at $500 \mathrm{kHz}$ are shown in Fig. 5.

It can be seen from Fig. 5 that the compared with the non-interleaved structure (Fig. 5a), in the partially interleaved structures (Fig. 5b), the highest magnetic field intensity is reduced, which is accordance with the analytical analysis.

Based on the distributions of the magnetic field intensity, the $L_{r}$ of each winding configuration can be calculated. The $L_{r}$ in each winding configuration versus frequency is shown in Fig. 6.

It may be concluded that compared with non-interleaved structures $\left(\mathrm{W}_{1}, \mathrm{~W}_{3}\right.$ and $\left.\mathrm{W}_{5}\right)$, the $\mathrm{L}_{\mathrm{r}}$ of the partially interleaved structures $\left(\mathrm{W}_{2}, \mathrm{~W}_{4}\right.$ and $\left.\mathrm{W}_{6}\right)$ are greatly reduced. Among the partially interleaved structures, the single-layer structure $\left(\mathrm{W}_{2}\right)$ and two-layer structure $\left(\mathrm{W}_{4}\right)$ share almost the same $\mathrm{L}_{\mathrm{r}}$, which is slightly lower than that of $\mathrm{W}_{6} . \mathrm{W}_{4}$ and $\mathrm{W}_{6}$ have the same MMF distribution and therefore the analytic formulas predict that they have the same $\mathrm{L}_{\mathrm{r}}$. However, because the turns in the two layers of $\mathrm{W}_{6}$ are shifted from one another, coupling between them is lower than in $\mathrm{W}_{4}$ where the turns on all winding layers are in the same radial location, and this results in higher $L_{r}$ for $\mathrm{W}_{6}$.

\section{Comparison of the calculation results and the simulation results}

The comparison of the simulation and the calculated results is shown in Fig. 7.

It can be seen that the calculated results show good agreement with the simulation results, which validates the effectiveness of the calculations. In order to operate at high switching frequency, a lower $\mathrm{L}_{\mathrm{r}}$ is required.

In this way, $\mathrm{W}_{2}$ and $\mathrm{W}_{4}$ are suitable for high switching frequency, high power density applications.

\section{AC REsistance}

The $R_{a c}$ is a significant parameter to determine the copper loss of a transformer, especially in high frequency applications,

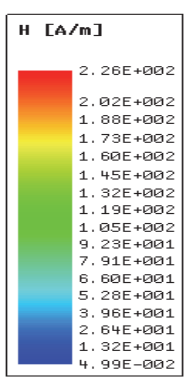

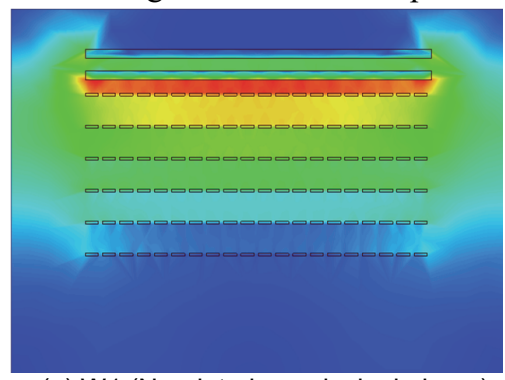

(a) W1 (Non-interleaved, single layer)
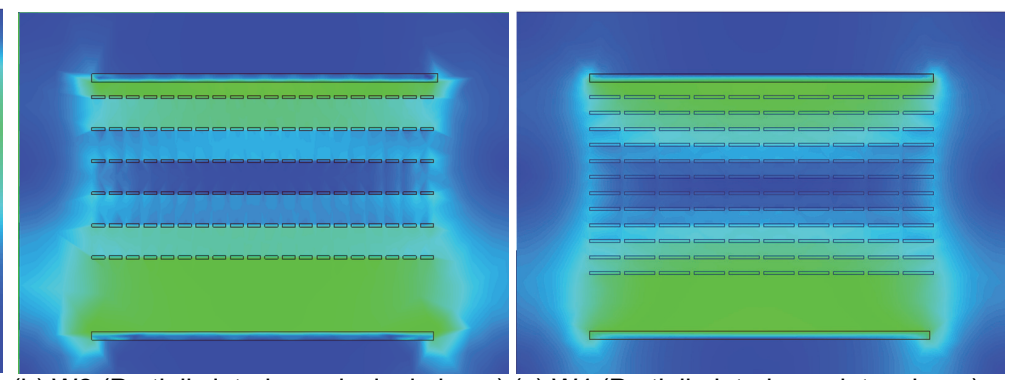

b) W2 (Partially interleaved, single layer) (c) W4 (Partially-interleaved, two-layer)

Fig. 5 Distributions of the magnetic field @ 500 kHz 


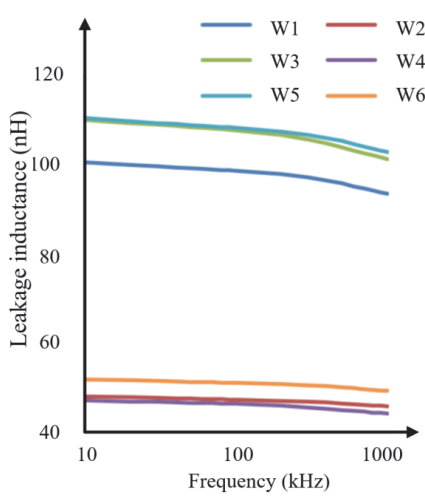

Fig. 6 Simulated leakage inductance Fig. 7 Comparison of leakage inducta

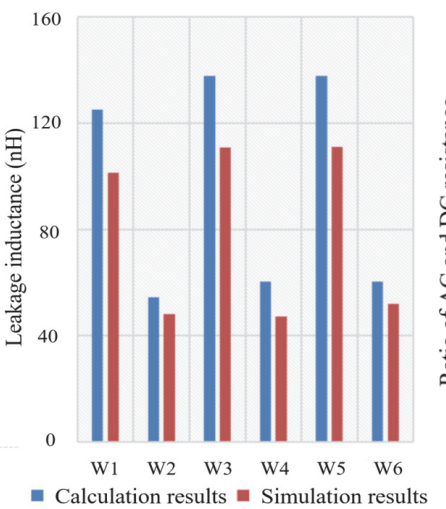

where the proximity effect and eddy skin effect will lead to the huge increase of the $R_{a c}$. In this section, the total AC/DC resistance referred to the primary side is analyzed. At first, the ratio of $\mathrm{AC} / \mathrm{DC}$ resistance referred to the primary side is simulated in FEA software to show the high-frequency characteristics. After that, in order to assess the copper loss, the $\mathrm{R}_{\mathrm{ac}}$ of each winding configuration referred to the primary side is simulated.

\section{A. The ratio of $A C / D C$ resistance}

The ratio of $\mathrm{AC} / \mathrm{DC}$ resistance can be used to reflect the high-frequency characteristics. The simulation results of the ratio of AC/DC resistance are shown in Fig. 8.

It can be seen from Fig. 8 that the $\mathrm{AC} / \mathrm{DC}$ resistance of the partially interleaved structures $\left(\mathrm{W}_{2}, \mathrm{~W}_{4}\right.$ and $\left.\mathrm{W}_{6}\right)$ is lower than that of the non-interleaved structures $\left(\mathrm{W}_{1}, \mathrm{~W}_{3}\right.$ and $\left.\mathrm{W}_{5}\right)$. It can be explained as follows. In the non-interleaved structure, higher leakage energy in the window leads to higher proximity effect, which means the conductors in the non-interleaved structures suffer more severe proximity effect.

As for the AC/DC resistance of $\mathrm{W}_{2}$ and $\mathrm{W}_{4}$, it can be seen from Fig. 5 that the distance between two adjacent layers in $\mathrm{W}_{2}$ is doubled compared with that of $\mathrm{W}_{4}$. In this way, the proximity effect is reduced further.

\section{B. AC resistance}

Although it is proved that $\mathrm{W}_{2}$ has the lowest ratio of $\mathrm{AC}$ and $\mathrm{DC}$ resistance, it should be noted that the $\mathrm{DC}$ resistance of $\mathrm{W}_{4}$ is lower than that of $\mathrm{W}_{2}$, which means that in the low-frequency range, the $\mathrm{AC}$ resistance of $\mathrm{W}_{4}$ is still lower than that of $\mathrm{W}_{2}$. Therefore, it is significant to investigate the absolute value of the $\mathrm{R}_{\mathrm{ac}}$.

The $R_{a c}$ is simulated in FEA software and the $R_{a c}$ versus frequency is shown in Fig. 9.

It can be seen from Fig. 9 that partially interleaved structures $\left(\mathrm{W}_{2}, \mathrm{~W}_{4}\right.$ and $\left.\mathrm{W}_{6}\right)$ have better high-frequency characteristics than the corresponding non-interleaved structures $\left(\mathrm{W}_{1}, \mathrm{~W}_{3}\right.$ and $\mathrm{W}_{5}$ ), which is in accordance with the previous analysis. In addition, the $\mathrm{R}_{\mathrm{ac}}$ of $\mathrm{W}_{4}$ is the lowest at low frequency (less than $500 \mathrm{kHz}$ ), mainly profiting from lower DC resistance. However, when the frequency increases to $500 \mathrm{kHz}$, the $\mathrm{R}_{\mathrm{ac}}$ of $\mathrm{W}_{4}$ increases to the same value as $\mathrm{W}_{2}$. When the switching frequency is higher, the $\mathrm{R}_{\mathrm{ac}}$ of $\mathrm{W}_{4}$ will be higher than that of
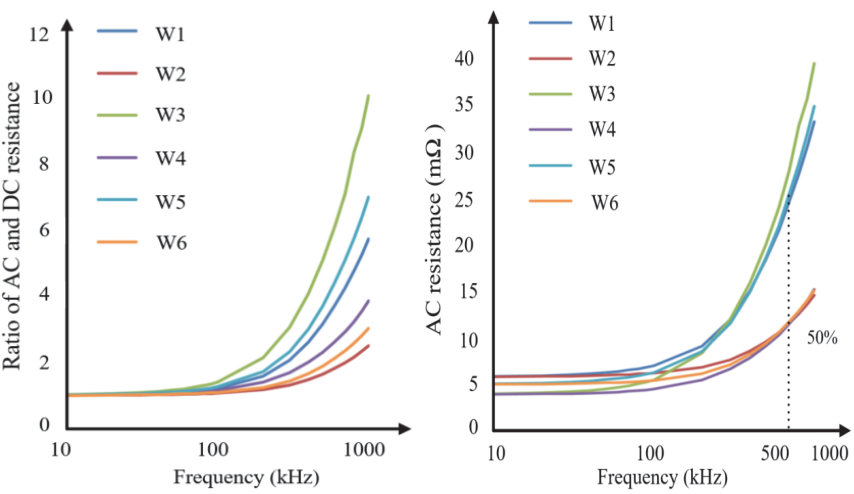

Fig. 8 AC/DC resistance

Fig. $9 \mathrm{AC}$ resistance

$\mathrm{W}_{2}$, which means less copper loss in $\mathrm{W}_{2}$ at high frequency (larger than $500 \mathrm{kHz}$ ).

Based on the above analysis, it can be concluded that under high frequency conditions, the partially interleaved, single layer structure, $\mathrm{W}_{2}$ has better high-frequency characteristics and lower copper loss. In addition, compared with the non-interleaved structure, the corresponding partially interleaved structure has $50 \%$ reduction in the $\mathrm{R}_{\mathrm{ac}}$. However, the critical frequency may vary from case to case and need further investigation according to the specific application.

\section{AC CAPACITANCE}

In the LCC and LCLC resonant converters, the AC capacitance $\left(\mathrm{C}_{\mathrm{p}}\right)$ of a transformer is used as a resonant component in the resonant tank. In the LCLC resonant converters, higher $C_{p}$ means more circulating energy, which will lead to higher conduction loss. Therefore, it is significant to investigate the winding configurations to find one with lower $\mathrm{C}_{\mathrm{p}}$.

The distributions of the $C_{p}$ in each structure are shown in Fig. 3. $\mathrm{C}_{\mathrm{ps} 1}$ and $\mathrm{C}_{\mathrm{ps} 2}$ are the parasitic capacitances between the primary winding and the secondary windings. $\mathrm{C}_{\mathrm{ss}}$ is the parasitic capacitance between two secondary windings. $C_{\text {intra }}$ is the parasitic capacitance between two layers in a secondary winding. $\mathrm{C}_{\text {inter }}$ is the parasitic capacitance between two adjacent turns in the same layer.

In this section, taking the voltage doublers into consideration, the $\mathrm{C}_{\mathrm{p}}$ of each winding configuration is calculated and the calculated results are validated by the simulation results.

\section{A. Calculation of AC capacitance}

The calculation of the $\mathrm{C}_{\mathrm{p}}$ referred to the primary side is based on the following method. Assuming $V_{p}$ is applied to the primary winding, the voltage per turn is $V_{p} / n_{p}$. Then the voltage of each turn both in the primary and secondary windings can be calculated. The $\mathrm{C}_{\mathrm{p}}$ referred to the primary side can be calculated by [14]

$$
C_{p}=\frac{2 E_{t o t}}{V_{p}^{2}}
$$

Where $E_{t o t}$ is the total electric energy stored in the window of the magnetic core. 
TABLE III

THE VOLTAGE (AC+DC) OF EACH TURN IN THE SECONDARY WINDINGS

\begin{tabular}{|c|c|c|c|c|c|c|c|c|c|c|c|c|c|c|c|c|c|c|c|c|}
\hline $\mathbf{T}$ & 1 & 2 & 3 & 4 & 5 & $\bar{~} 6$ & 7 & 8 & 9 & 10 & 11 & 12 & 13 & 14 & 15 & 16 & 17 & 18 & 19 & 20 \\
\hline $\mathbf{W}_{1}$ & 0.5 & 1.0 & 1.5 & 2.0 & 2.5 & 3.0 & 3.5 & 4.0 & 4.5 & 5.0 & 5.5 & 6.0 & 6.5 & 7.0 & 7.5 & 8.0 & 8.5 & 9.0 & 9.5 & 10 \\
\hline $\mathbf{W}_{2}$ & 20.5 & 21 & 21.5 & 22 & 22.5 & 23 & 23.5 & 24 & 24.5 & 25 & 25.5 & 26 & 26.5 & 27 & 27.5 & 28 & 28.5 & 29 & 29.5 & 30 \\
\hline $\mathbf{W}_{3}$ & 40.5 & 41 & 41.5 & 42 & 42.5 & 43 & 43.5 & 44 & 44.5 & 45 & 45.5 & 46 & 46.5 & 47 & 47.5 & 48 & 48.5 & 49 & 49.5 & 50 \\
\hline $\mathbf{W}_{4}$ & 60.5 & 61 & 61.5 & 62 & 62.5 & 63 & 63.5 & 64 & 64.5 & 65 & 65.5 & 66 & 66.5 & 67 & 67.5 & 68 & 68.5 & 69 & 69.5 & 70 \\
\hline$W_{5}$ & 80.5 & 81 & 81.5 & 82 & 82.5 & 83 & 83.5 & 84 & 84.5 & 85 & 85.5 & 86 & 86.5 & 87 & 87.5 & 88 & 88.5 & 89 & 89.5 & 90 \\
\hline $\mathbf{W}_{6}$ & 100. & 10 & 101. & 10 & 102. & 10 & 103. & 10 & 104. & 10 & 105. & 10 & 106. & 10 & 107. & 10 & 108. & 10 & 109. & 110 \\
\hline & 5 & 1 & 5 & 2 & 5 & 3 & 5 & 4 & 5 & 5 & 5 & 6 & 5 & 7 & 5 & 8 & 5 & 9 & 5 & \\
\hline
\end{tabular}

TABLE IV

THE VOLTAGE (AC) OF EACH TURN IN THE SECONDARY WINDINGS

\begin{tabular}{|c|c|c|c|c|c|c|c|c|c|c|c|c|c|c|c|c|c|c|c|c|}
\hline $\mathbf{T}$ & 1 & 2 & 3 & 4 & 5 & 6 & 7 & 8 & 9 & 10 & 11 & 12 & 13 & 14 & 15 & 16 & 17 & 18 & 19 & 20 \\
\hline $\mathbf{W}_{1}$ & 0.5 & 1.0 & 1.5 & 2.0 & 2.5 & 3.0 & 3.5 & 4.0 & 4.5 & 5.0 & 5.5 & 6.0 & 6.5 & 7.0 & 7.5 & 8.0 & 8.5 & 9.0 & 9.5 & 10 \\
\hline $\mathbf{W}_{2}$ & 0.5 & 1.0 & 1.5 & 2.0 & 2.5 & 3.0 & 3.5 & 4.0 & 4.5 & 5.0 & 5.5 & 6.0 & 6.5 & 7.0 & 7.5 & 8.0 & 8.5 & 9.0 & 9.5 & 10 \\
\hline $\mathbf{W}_{3}$ & 0.5 & 1.0 & 1.5 & 2.0 & 2.5 & 3.0 & 3.5 & 4.0 & 4.5 & 5.0 & 5.5 & 6.0 & 6.5 & 7.0 & 7.5 & 8.0 & 8.5 & 9.0 & 9.5 & 10 \\
\hline $\mathbf{W}_{4}$ & 0.5 & 1.0 & 1.5 & 2.0 & 2.5 & 3.0 & 3.5 & 4.0 & 4.5 & 5.0 & 5.5 & 6.0 & 6.5 & 7.0 & 7.5 & 8.0 & 8.5 & 9.0 & 9.5 & 10 \\
\hline$W_{5}$ & 0.5 & 1.0 & 1.5 & 2.0 & 2.5 & 3.0 & 3.5 & 4.0 & 4.5 & 5.0 & 5.5 & 6.0 & 6.5 & 7.0 & 7.5 & 8.0 & 8.5 & 9.0 & 9.5 & 10 \\
\hline$W_{6}$ & 0.5 & 1.0 & 1.5 & 2.0 & 2.5 & 3.0 & 3.5 & 4.0 & 4.5 & 5.0 & 5.5 & 6.0 & 6.5 & 7.0 & 7.5 & 8.0 & 8.5 & 9.0 & 9.5 & 10 \\
\hline
\end{tabular}

In this case, the electric energy contains four parts: the electric energy stored between the primary winding $\left(E_{p p}\right)$, between the primary winding and the secondary windings $\left(E_{p s}\right)$, the electric energy stored in the secondary windings, the electric energy stored between two secondary windings $\left(E_{s s}\right)$.

The electric energy in the primary winding is

$$
E_{p p}=\frac{1}{2} \sum_{i=1}^{m-1} C_{p p_{-} i} V_{p p_{-} i}^{2}
$$

Where $C_{p p_{-} i}$ is the parasitic capacitance between two turns in the primary winding. $V_{p p} i$ is the voltage of the capacitance.

The electric energy stored between the primary windings and the secondary windings can be calculated by

$$
E_{p s}=\frac{1}{2} \sum_{i=1}^{2} C_{p s_{-} i} V_{p s_{-} i}^{2}
$$

Where $C_{p p_{-} i}$ is the parasitic capacitance between two turns in the primary winding. $V_{p p_{i} i}$ is the voltage of the capacitance.

The energy stored in a secondary winding contains two parts. The first part is the electric energy stored between two adjacent turns in the same layer, which can be calculated by

$$
E_{\text {int } e r}=\frac{1}{2} \sum_{i=1}^{N S-1} C_{\text {inter }_{-} i} V_{\text {inter }}^{2} i
$$

Where $N_{s}$ is the number of the turns in a secondary winding. $\mathrm{C}_{\text {inter } i}$ is the capacitance between two adjacent turns in the same layer, which can be calculated by the equation for the plane-parallel capacitor. $V_{\text {intra } i}$ is the voltage between two adjacent turns, which is $V_{p} / n_{p}$.

The second part is the electric energy stored between two layers in a secondary winding, which can be calculated by

$$
E_{\text {int } r a}=\frac{1}{2} \sum_{i=1}^{N s / 2} C_{\text {int } r a_{-}} V_{\text {int } r a_{-} i}^{2}
$$

Where $C_{\text {intra } i}$ is the capacitance between two layers in a secondary winding, which can be calculated by the equation for the plane-parallel capacitor.

The electric energy stored between two adjacent secondary windings can be calculated by

$$
E_{s s}=\frac{1}{2} \sum_{i=1}^{N s / 2} C_{s s_{-} i} V_{s s_{-} i}^{2}
$$

Where $C_{S S ~} i$ is the capacitance between two adjacent secondary windings.
As a result, the total electric energy of a system is the sum of the electric energy stored in all the capacitors in the system, which can be calculated by

$$
E_{\text {tot }}=\sum_{j=1}^{m-1} E_{p p_{-} j}+\sum_{j=1}^{t} E_{p s_{-} j}+\sum_{j=1}^{n-1} E_{\mathrm{int} e r_{-} j}+\sum_{j=1}^{n-1} E_{\mathrm{int} e r_{-} j}+\sum_{j=1}^{n-1} E_{s s_{-} j}
$$

Where $t$ is one in the non-interleaved structure and two in the partially interleaved structure.

Substituting (10) into (5), the $C_{p}$ referred to the primary side can be calculated by

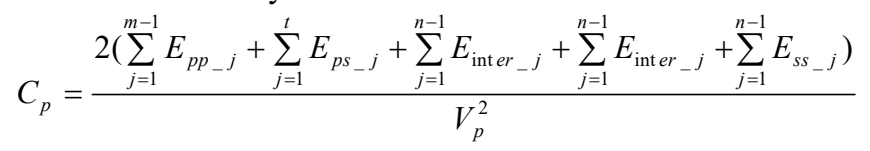

However, in the high-voltage multiple-output applications, as shown in Fig. 1, since the output of each secondary winding is connected to a voltage doubler and in series with the other secondary winding, there is an increasing DC component across the winding capacitance, which is caused by the capacitors $\left(\mathrm{C}_{1}, \mathrm{C}_{2} \ldots\right.$, and $\left.\mathrm{C}_{\mathrm{n}}\right)$ in the voltage doubler. Assuming $1 \mathrm{~V}$ is applied to the primary winding, the voltage of each turn with the DC component in the secondary windings is listed in Table III.

Using the equations (6), (7), (8), (9), (10) and (11), and the AC voltage excitations in Table IV, the $C_{p}$ referred to the primary winding in each winding configuration is calculated and calculated results are shown in Table V.

The following simulation results will validate the calculated results.

\section{B. Simulation results of $C_{p}$}

In order to validate the calculated results, the $C_{p}$ is simulated in the electrostatic solver of Ansys Maxwell with the same voltage boundary conditions applied as in calculations. The distributions of the electric field intensity in $\mathrm{W}_{1}, \mathrm{~W}_{2}$ and $\mathrm{W}_{5}$ are shown in Fig. 10. For ease of comparison, all the color maps in Fig. 10 are produced to the same scale.

The $C_{p}$ is calculated by the electric field energy. The simulated results are shown in Fig. 11. In order to facilitate comparison, the calculated results are included in Fig. 11 as well. 


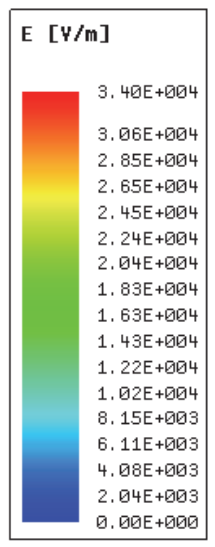

It can be seen from Fig. 11 that the calculation results are in accordance with the simulation results, which validates the accuracy of the calculations. The $\mathrm{C}_{\mathrm{p}}$ of the partially interleaved structure is slightly higher than that of the corresponding non-interleaved structure because the partially interleaved structure causes extra capacitance between the primary winding and the secondary winding.

Among the three partially interleaved structures $\left(\mathrm{W}_{2}, \mathrm{~W}_{4}\right.$ and $\mathrm{W}_{6}$ ), $\mathrm{W}_{4}$ has the highest $\mathrm{C}_{\mathrm{p}}$, which can be explained by the following two reasons. Firstly, in the two-layer structure, half of the turns are on one layer while the other half are on another neighboring layer. As a result, there is high intra-winding capacitance $\left(C_{\text {intra }}\right)$, which is shown in Fig. 2 . In addition, the overlapped winding area in $\mathrm{W}_{4}$ is the largest. Compared with $\mathrm{W}_{4}$, the $\mathrm{C}_{\mathrm{p}}$ of $\mathrm{W}_{6}$ is much lower, mainly because the overlapped area is reduced. However, the large intra-winding capacitance ( $C_{\text {intra }}$ ) still exists, which mainly contributes to the AC capacitance of $\mathrm{W}_{6}$. $\mathrm{W}_{2}$ has the lowest capacitance among all the partially interleaved structures. All the turns are in one layer while the other layer is used for the outgoing line only. In this way, $C_{\text {intra }}$ is reduced greatly. As a result, the $C_{p}$ of the single-layer structure is reduced.

\section{COMPARISON OF THE TRANSFORMER DESIGN}

\section{A. Effect of the transformer design on resonant}

\section{converter operation}

The analysis about the parastics is summarized in Table VII. In the resonant converters, the parasitic parameters of the transformer will be utilized in the resonant tank and have crucial effect on the performance of the converter:

Effect of $\mathrm{Lr}_{r}$. With higher leakage inductance $\left(\mathrm{L}_{\mathrm{r}}\right)$, the switching frequency will be reduced, which will lead to the increase in the volume of the passive components, such as the inductors, transformers and the filter capacitors. For high-voltage applications, it is desirable that the transformer has low $\mathrm{L}_{\mathrm{r}}$. As a result, it can be seen from Table VII that the partially interleaved structures $\left(\mathrm{W}_{2}, \mathrm{~W}_{4}\right.$ and $\left.\mathrm{W}_{6}\right)$ are suitable for high-frequency applications.

Effect of $\mathbf{R}_{\mathbf{a c}}$. The copper loss is main part of the power loss in a transformer. In order to reduce the copper loss, a winding configuration with low $A C$ resistance $\left(\mathrm{R}_{\mathrm{ac}}\right)$ is better than others. It can be seen from Table VII that taking the high-frequency application (higher than $500 \mathrm{kHz}$ ) into consideration, $\mathrm{W}_{2}, \mathrm{~W}_{4}$ and $\mathrm{W}_{6}$ have relative lower $\mathrm{R}_{\mathrm{ac}}$.

Effect of the $\mathbf{C}_{\mathbf{p}}$. As for the parasitic capacitance $\left(\mathrm{C}_{\mathrm{p}}\right)$ of a transformer, a larger $C_{p}$ will lead to high current to charge and discharge the capacitance and the conduction loss will increase. For low power loss considerations, a winding structure with low $\mathrm{C}_{\mathrm{p}}$ is desirable. As a result, it can be seen from Table VII that $\mathrm{W}_{1}$ and $\mathrm{W}_{2}$, featured with low $\mathrm{C}_{\mathrm{p}}$, are desirable.

As a result, it can be concluded that from different points of

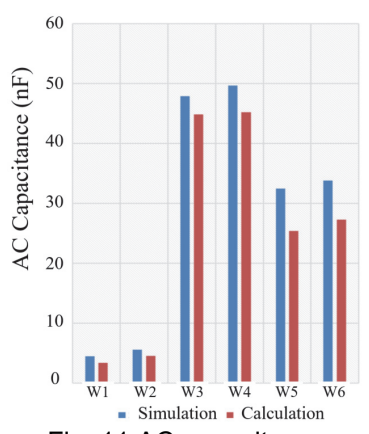

TABLE VI

\begin{tabular}{cc}
\multicolumn{2}{c}{ CalCulation OF AC } \\
CAPACITANCE \\
\hline \hline Winding & $\mathrm{C}_{\mathrm{p}}$ \\
$\mathrm{W}_{1}$ & 6.72 \\
$\mathrm{~W}_{2}$ & 9.0 \\
$\mathrm{~W}_{3}$ & 44.83 \\
$\mathrm{~W}_{4}$ & 45.2 \\
$\mathrm{~W}_{5}$ & 25.4 \\
$\mathrm{~W}_{6}$ & 27.3 \\
\hline \hline
\end{tabular}

\section{VOLTAGE EXCITATIONS}

Winding $(\mathrm{V}$ (Itage $(\mathrm{kV})$

\begin{tabular}{lc} 
Winding & Voltage $(\mathrm{kV})$ \\
$\mathrm{P}_{\text {and }} \mathrm{S}_{1}$ & 1.2 \\
$\mathrm{~S}_{1}$ and $\mathrm{S}_{2}$ & 1.2 \\
$\mathrm{~S}_{2}$ and $\mathrm{S}_{3}$ & 1.2 \\
$\mathrm{~S}_{3}$ and $\mathrm{S}_{4}$ & 1.2 \\
$\mathrm{~S}_{4}$ and $\mathrm{S}_{5}$ & 1.2 \\
$\mathrm{~S}_{5}$ and $\mathrm{S}_{6}$ & 7.5 \\
\hline
\end{tabular}

TABLE VII

SUMMARY OF THE PARASITICS VOLTAGE EXCITATIONS IN ELECTRIC

\begin{tabular}{cccc}
\multicolumn{4}{c}{ INSULATION TEST } \\
\hline \hline Winding & $\mathrm{L}_{\mathrm{r}}(\mathrm{nH})$ & $\mathrm{R}_{\mathrm{ac}}(\mathrm{m} \Omega)$ & $\mathrm{Cp}$ \\
& $(500 \mathrm{kHz})$ & $(500 \mathrm{kHz})$ & $(\mathrm{nF})$ \\
$\mathrm{W}_{1}$ & 95.5 & 18.38 & 8.72 \\
$\mathrm{~W}_{2}$ & 46.4 & 9.6 & 11.1 \\
$\mathrm{~W}_{3}$ & 103.6 & 20 & 44.83 \\
$\mathrm{~W}_{4}$ & 44.9 & 9.14 & 45.2 \\
$\mathrm{~W}_{5}$ & 105.0 & 18.54 & 25.4 \\
$\mathrm{~W}_{6}$ & 50.16 & 9.43 & 27.3 \\
\hline \hline
\end{tabular}

Fig. 11 AC capacitance 


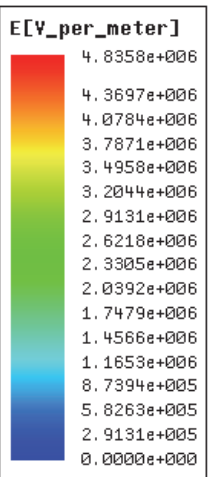

(a) Electric field intensity field distributions of W1

Fig. 12 Simulations of the electric fie

view, the optimal design result will be different, which means the design of the planar transformer needs tradeoff. In this case, taking all the parasitics into consideration, $W_{2}$, which is featured with low $L_{r}$, low $C_{p}$ and low $R_{a c}$ is suitable for high-voltage high-frequency multiple-output applications.

\section{B. Analysis of the partial discharge}

Partial discharge is a big issue in high-voltage transformers. In this paper, as the partially interleaved structure is applied, it is necessary to analyze the effect of the partially interleaving on the partial discharge.

Comparison of the partially interleaving and non-interleaving is carried out between $\mathrm{W}_{1}$ and its corresponding partial interleaved structure $\mathrm{W}_{2}$. The voltage of each turn under the real working conditions is applied to the corresponding turn, where the input voltage is $40 \mathrm{~V}$, the highest output voltage is $4800 \mathrm{~V}$. The distributions of the electric field intensity are shown in Fig. 12. It should be noted that Fig. 10 shows the AC electric field distribution only while Fig. 12 shows the magnitude of the combined DC and AC electric fields.

It can be seen from Fig. 12 that the highest electric field intensity of $\mathrm{W}_{2}\left(5.84 \times 10^{6} \mathrm{~V} / \mathrm{m}\right)$ is slightly higher than that of $\mathrm{W}_{1}\left(4.84 \times 10^{6} \mathrm{~V} / \mathrm{m}\right)$, which is caused by the partially interleaving. However, the highest electric field can be reduced by the increase of the insulation.

As a result, it can be concluded that the partially interleaving will increase the partial discharge. However, the increase in partial discharge can be optimized by increasing the thickness of the insulation.

\section{EXPERIMENTAL VALIDATION}

\section{A. Planar transformer for high-voltage high-frequency applications}

Based on the above discussion about the comparison of the transformer design, a planar transformer with the partially-interleaved single-layer structure for a $40 \mathrm{~V}$ input, $4800 \mathrm{~V}$ output LCLC resonant converter was built. The planar transformer uses the same parameters as listed in Table I.

The shape of the core for the planar transformer is FEE $38 / 16 / 25$ and the material is N87. The planar transformer has one primary winding and six secondary windings. The primary winding has two turns. In order to achieve a partially interleaved structure, one turn is placed at the top of the PCB $\left(\mathrm{P}_{1}\right)$ while the other is at the bottom $\left(\mathrm{P}_{2}\right)$. The six secondary windings $\left(\mathrm{S}_{1}, \mathrm{~S}_{2}, \mathrm{~S}_{3}, \mathrm{~S}_{4}, \mathrm{~S}_{5}\right.$ and $\left.\mathrm{S}_{6}\right)$ are located between the
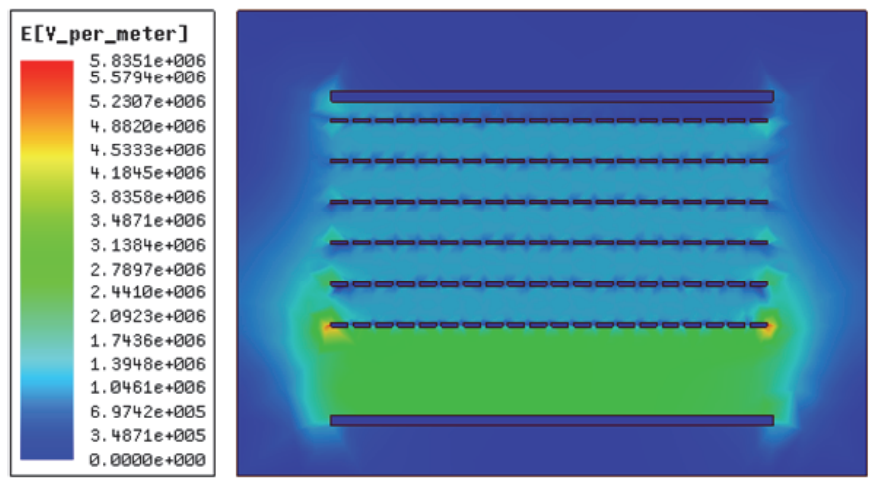

(b) Electric field intensity distributions of W2

primary winding and each secondary winding has twenty turns with the single-layer structure. As the output voltage increases from $S_{1}$ at the top to $S_{6}$ at the bottom, which means the voltage of $S_{1}$ is the lowest while that of $S_{6}$ is the highest, in order to satisfy the requirement of the high-voltage insulation, a thicker insulation is added between secondary winding $\left(\mathrm{S}_{6}\right)$ and the bottom primary winding $\left(\mathrm{P}_{2}\right)$.

\section{B. Testing of the planar transformer}

The planar transformer was tested with a HP 4940 impedance analyzer. The test results are shown in Fig. 13.

The $L_{r}$ is measured from the primary winding with the secondary windings short circuit. It can be seen from Fig. 13(a) that $\mathrm{L}_{\mathrm{r}}$ is $54.9 \mathrm{nH}$, which shows small relative error compared with the calculation result $(54.54 \mathrm{nH})$ and the simulation result (48.04 nH). $\mathrm{L}_{\mathrm{m}}$ is $3.9 \mu \mathrm{H}$.

When the secondary side is open circuit, as $\mathrm{L}_{\mathrm{r}}$ is much lower than that $\mathrm{L}_{m}$, the resonant frequency between $\mathrm{L}_{\mathrm{m}}$ and $\mathrm{C}_{\mathrm{p}}$ is measured by the impedance analyzer as shown in Fig. 13(b):

$$
f_{r}=\frac{1}{2 \pi \sqrt{L_{m} C_{p}}}
$$

Where $f_{r}$ is the resonant frequency, which can be read from

the measured result impedance versus frequency results under open-circuit conditions.
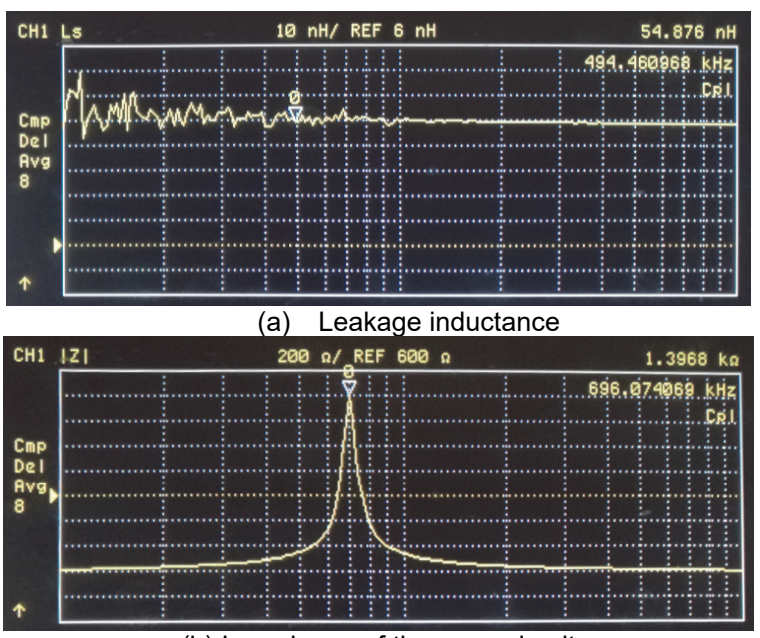

(b) Impedance of the open circuit

Fig. 13 Test results of the high voltage planar transformer

Therefore, $C_{p}$ of the planar transformer is found to be

$$
C_{p}=13.2 \mathrm{nF}
$$




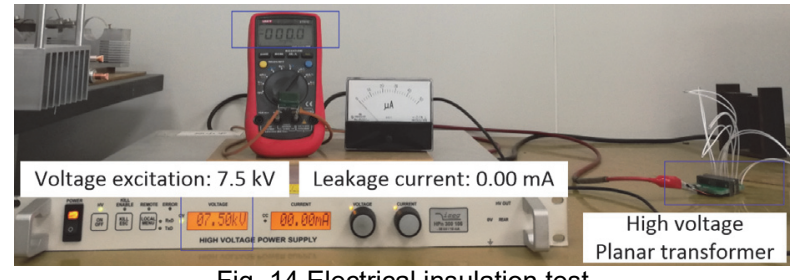

Fig. 14 Electrical insulation test

The measured $C_{p}$ shows acceptable relative error compared with the simulation result $(11.1 \mathrm{nF})$ and the calculation result $(9.0 \mathrm{nF})$.

For high-voltage applications, the effectiveness of the high voltage insulation must be tested. The test is carried out between each of the adjacent windings $\left(\mathrm{P}\right.$ and $\mathrm{S}_{1}, \mathrm{~S}_{1}$ and $\mathrm{S}_{2}, \mathrm{~S}_{2}$ and $\mathrm{S}_{3}, \mathrm{~S}_{3}$ and $\mathrm{S}_{4}, \mathrm{~S}_{4}$ and $\mathrm{S}_{5}, \mathrm{~S}_{5}$ and $\mathrm{S}_{6}, \mathrm{P}$ and $\mathrm{S}_{6}$ ). The voltage excitations applied to the windings are listed in Table VI. The test of the electrical insulation between $\mathrm{P}$ and $\mathrm{S}_{6}$ (highest voltage, $7.5 \mathrm{kV}$ ) is shown in Fig. 14.

It can be seen from the current meter that the leakage current is zero, which proves the effectiveness of the electrical insulation.

\section{Testing of the planar transformer in an LCLC resonant converter}

The LCLC resonant converter with fixed-frequency fixed-duty cycle as a DC transformer is widely used in the second stage of a two-stage converter [16]. There are four resonant elements in the resonant tank: $\mathrm{L}_{\mathrm{r}}, \mathrm{C}_{\mathrm{s}}, \mathrm{L}_{\mathrm{m}}$ and $\mathrm{C}_{\mathrm{p}}$. All the transformer parasitics are incorporated into the resonant tank and only $\mathrm{C}_{\mathrm{s}}$ is needed.

The LCLC resonant converter with the planar transformer is shown in Fig. 15. The input voltage is $40 \mathrm{~V}$, the output of each secondary winding is connected to a voltage doubler to produce $800 \mathrm{~V}$. The outputs of the six voltage doublers are connected in series. As a result, each output of a voltage doubler can be used for a separate load and the maximum output voltage is $4800 \mathrm{~V}$.

The measured waveforms of the resonant current $i_{r}(t)$, the voltage and the driving signal of $\mathrm{S}_{1}$ in the LCLC resonant converter with the planar transformer are shown in Fig. 16, where it can be seen that the switching frequency of the converter is $500 \mathrm{kHz}$.

It can be seen from Fig. 16(a) that when $S_{1}$ is turned on, the voltage of $S_{1}$ is zero and the resonant current is also zero, therefore, $\mathrm{S}_{1}$ operations with Zero-Voltage-Switching (ZVS) and Zero-Current-Switching (ZCS). The switching loss is minimized. The voltage and current of the rectifier diode $\mathrm{D}_{1}$ is shown in Fig. 16(b). ZCS and ZVS are also achieved, which will reduce the switching loss.

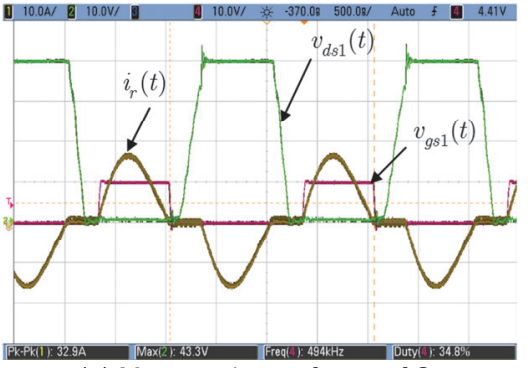

(a) Measured waveforms of S

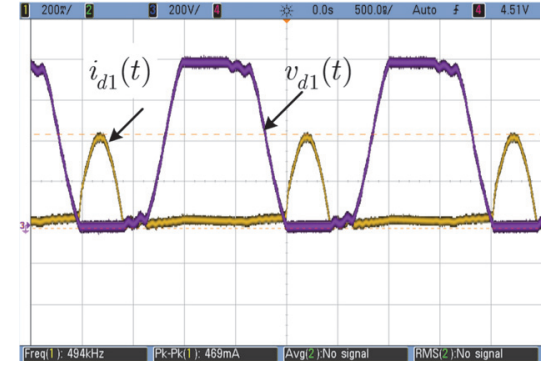

(b) Measured waveforms of the rectifier $D_{1}$
Fig. 16 Measured results

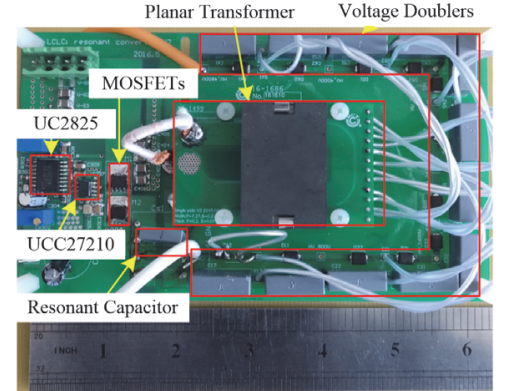

Fig. 15 LCLC resonant converter with a high voltage planar transformer

The efficiency of the converter under different input voltages is tested and is shown in Fig. 17. When the input voltage is $40 \mathrm{~V}$, the input current is $7.35 \mathrm{~A}$, the output is $4800 \mathrm{~V}$, the output current is $59.88 \mathrm{~mA}$, and the load is $80 \mathrm{k} \Omega$, the efficiency is $96.8 \%$.

\section{Loss breakdown of the LCLC resonant converter}

In this part, the power loss of the LCLC resonant converter is derived based on circuit simulation, including the driving loss $\left(P_{S_{-} d r}\right)$, conduction loss of the switches $\left(P_{S_{-} o n}\right)$, copper loss $\left(P_{T_{C} \mathrm{Cu}}\right)$, core loss $\left(P_{T_{-} \mathrm{Fe}}\right)$ and dielectric loss $\left(P_{T_{-} \mathrm{Die}}\right)$ of the planar transformer and the rectifier loss $\left(P_{D}\right)$.

As for the power loss of the high voltage planar transformer, in addition to the conventional copper loss and core loss, the dielectric loss is also considered in this case. The dielectric loss is caused by the charging and discharging process of the parasitic capacitance. In this case, the power loss factor $(\tan \delta)$ of FR4 is 0.01 , according to the definition of the power loss factor

$$
\tan \delta=2 \pi f_{s} C_{p} R_{s}
$$

Where $R_{s}$ is the equivalent series resistance, $f_{s}$ is the switching frequency of the capacitance, $C_{p}$ is the value of the capacitance.

The dielectric loss $\left(P_{T_{-} \text {Die }}\right)$ can be calculated by

$$
P_{T_{-} \text {Die }}=I_{c_{-} r m s}^{2} R_{s}
$$

Where $I_{c_{-} r m s}$ is the RMS current across the parasitic capacitance, which can be derived from the circuit simulation.

The rectifier loss is calculated by the forward voltage $\left(V_{R}\right)$ times the average current $\left(I_{a v}\right)$ :

$$
P_{D}=V_{R} I_{a v}
$$

The total loss $\left(P_{t o t}\right)$ can be calculated by

$$
P_{\text {tot }}=P_{S_{-} d r}+P_{S_{-} \text {on }}+P_{T_{-} \mathrm{Cu}}+P_{T_{-} F e}+P_{T_{-} \text {Die }}+P_{D}
$$

The power loss of each part is derived from circuit 


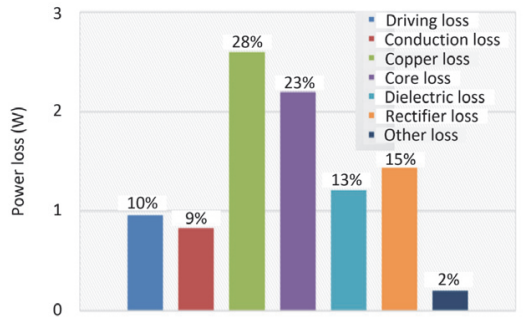

Fig. 18 Loss breakdown of the LCLC resonant converter

simulation and the loss breakdown is shown in Fig. 18. The simulated $P_{t o t}$ is $9.24 \mathrm{~W}$ while the measured $P_{t o t}$ is $9.44 \mathrm{~W}$. It can be concluded that the simulated $P_{t o t}$ is in accordance with the measured result.

The power loss of the switches (driving loss and conduction loss) account for $19 \%$, which is relatively high in the total power loss. However, this can be improved by replacing the Silicon MOSFETs by GaN MOSFETs. The power loss of the transformer accounts for $64 \%$, which is the highest in the total loss. As for the dielectric loss, the Polyimide PCB with lower power loss factor, which will contribute to the reduction of the equivalent series resistance, can be used.

According to Table VII, when other winding configurations are compared with $\mathrm{W}_{2}$, the non-interleaved structures $\left(\mathrm{W}_{1}, \mathrm{~W}_{3}\right.$ and $\mathrm{W}_{5}$ ) will limit the high switching frequency due to higher leakage inductance compared with the partially interleaved structures $\left(\mathrm{W}_{2}, \mathrm{~W}_{4}\right.$ and $\left.\mathrm{W}_{6}\right)$. In addition, compared with $\mathrm{W}_{2}, \mathrm{~W}_{4}$ and $\mathrm{W}_{6}$ will suffer from higher conduction loss and copper loss due to high AC capacitance.

\section{CONCLUSIONS}

A partially-interleaved single-layer structure for high-voltage high-frequency multiple-output applications is proposed in this paper. The parasitic capacitance is considered and this transformer structure manages to do the trade-off design among all the parasitic parameters. Based on leakage inductance, $\mathrm{AC} / \mathrm{DC}$ resistance and $\mathrm{AC}$ capacitance, this structure is compared with other five typical structures. Simulations and calculations show that both the leakage inductance and the AC/DC resistance are reduced. In addition, this structure shares almost the same AC capacitance with the non-interleaved single-layer structure.

Besides, a planar transformer with the partially-interleaved single-layer structure is built and tested with the LCLC resonant topology. Compared with the state of the art in TWTA application, by careful design of a planar transformer, leakage inductance is reduced while maintaining inter-winding capacitance within values that ensure ZVS and ZCS, with the result that the switching frequency is increased from less than $100 \mathrm{kHz}$ to $500 \mathrm{kHz}$ without any decrease in efficiency.

Therefore, based on the above analysis, it may be concluded that the partially-interleaved single-layer structure proposed in this paper is suitable for high-voltage high-frequency multiple output applications.

It should be noted that the analysis in this paper considered a particular application, however, due to the improvement in leakage inductance, $\mathrm{AC}$ capacitance and $\mathrm{AC}$ resistance, the case of partial interleaving would provide similar benefits in other high voltage applications having high step-up and isolation requirements.

\section{REFERENCES}

[1] Barbi, I. and R. Gules, "Isolated DC-DC converters with high-output voltage for TWTA telecommunication satellite applications". IEEE Trans. on Power Electronics, 18(4): pp. 975-984, 2003.

[2] K. Liu, R. Fu, Y. Gao, Y. Sun and P. Yan, "High-Voltage Repetition-Frequency Charging Power Supply for Pulsed Laser," IEEE Trans. on Plasma Science, vol. 43, no. 5, pp. 1387-1392.

[3] J. A. Sabaté, R. R. Wang, F. Tao and S. Chi, "Magnetic Resonance Imaging Power: High-Performance MVA Gradient Drivers," IEEE Journal of Emerging and Selected Topics in Power Electronics, vol. 4 , no. 1, pp. 280-292, March 2016.

[4] X. She, A. Q. Huang, Ó. Lucía and B. Ozpineci, "Review of Silicon Carbide Power Devices and Their Applications," IEEE Trans. on Industrial Electronics, vol. 64, no. 10, pp. 8193-8205, Oct. 2017.

[5] E. Gurpinar and A. Castellazzi, "Single-Phase T-Type Inverter Performance Benchmark Using Si IGBTs, SiC MOSFETs, and GaN HEMTs," IEEE Trans. on Power Electronics, vol. 31, no. 10, pp. 7148-7160, Oct. 2016.

[6] R. Khazaka, L. Mendizabal, D. Henry and R. Hanna, "Survey of High-Temperature Reliability of Power Electronics Packaging Components," IEEE Trans. on Power Electronics, vol. 30, no. 5, pp. 2456-2464, May 2015.

[7] C. Fei, F. C. Lee and Q. Li, "High-Efficiency High-Power-Density LLC Converter With an Integrated Planar Matrix Transformer for High-Output Current Applications," IEEE Trans. on Industrial Electronics, vol. 64, no. 11, pp. 9072-9082, Nov. 2017.

[8] J. Biela and J. W. Kolar, "Using Transformer Parasitics for Resonant Converters - A Review of the Calculation of the Stray Capacitance of Transformers," IEEE Trans. on Industry Applications, vol. 44, no. 1, pp. 223-233, Jan.-Feb. 2008.

[9] J. Liu, L. Sheng, J. Shi, Z. Zhang and X. He, "Design of High Voltage, High Power and High Frequency Transformer in LCC Resonant Converter," in Proc. 2009 Twenty-Fourth Annual IEEE Applied Power Electronics Conference and Exposition, Washington, DC, 2009, pp. 1034-1038.

[10] J. Zhang, Z. Ouyang, M. C. Duffy, M. A. E. Andersen and W. G. Hurley, "Leakage Inductance Calculation for Planar Transformers With a Magnetic Shunt," IEEE Trans. on Industry Applications, vol. 50, no. 6, pp. 4107-4112, Nov.-Dec. 2014

[11] N. H. Baars, J. Everts, C. G. E. Wijnands and E. A. Lomonova, "Performance Evaluation of a Three-Phase Dual Active Bridge DC-DC Converter With Different Transformer Winding Configurations," IEEE Trans. on Power Electronics, vol. 31, no. 10, pp. 6814-6823, Oct. 2016.

[12] R. Pittini, Zhe Zhang, Z. Ouyang, M. A. E. Andersen and O. C. Thomsen, "Analysis of planar E+I and ER+I transformers for low-voltage high-current DC/DC converters with focus on winding losses and leakage inductance," in Proc. 7th International Power Electronics and Motion Control Conference, Harbin, China, 2012, pp. 488-493.

[13] Y. Guan, N. Qi, Y. Wang, X. Zhang, D. Xu and W. Wang, "Analysis and design of planar inductor and transformer for resonant converter," in Proc. 2016 IEEE Energy Conversion Congress and Exposition (ECCE), Milwaukee, WI, 2016, pp. 1-7.

[14] B. Zhao, Z. Ouyang, M. Duffy, M. A. E. Andersen and W. G. Hurley, "An Improved Partially Interleaved Transformer Structure for High-voltage High-frequency Multiple-output Applications", in Proc. IECON 2017 -

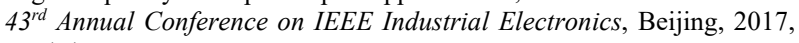
pp. 1-1.

[15] J. L. Wu, E. S. Ortoli and D. T. Hackworth, "Electrical Insulation Performance Comparisons between Kapton and Teflon Coil Insulation Systems for Pulse Power Applications," in Proc. 2008 14th Symposium on Electromagnetic Launch Technology, Victoria, BC, 2008, pp. 1-6.

[16] B. Zhao; G. Wang; G. Hurley, "Analysis and Performance of LCLC Resonant Converters for High-voltage High-frequency Applications," IEEE Journal of Emerging and Selected Topics in Power Electronics, vol. 5 no. 99 , pp. $1272-1286$.

[17] Z. Ouyang, J. Zhang and W. G. Hurley, "Calculation of Leakage Inductance for High-Frequency Transformers," IEEE Trans. on Power Electronics, vol. 30, no. 10, pp. 5769-5775. 


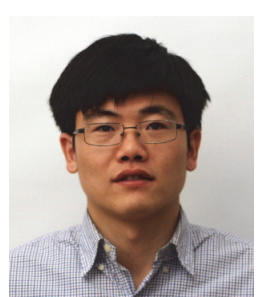

Bin Zhao received the B. S. degree in electrical engineering from Nanjing Agricultural University, Nanjing, China, in 2012 and the Ph.D. degree from Institute of Electronics, Chinese Academy of Sciences, Beijing, China, in 2017.

From September 2015 to December 2016, he was a Visiting Scholar with the National University of Ireland, Galway, Ireland. He is currently with the Department of Electrical Engineering, Technical University of Denmark, as a Postdoctoral Researcher. His current research interests include high frequency magnetic simulation, design and integration in power electronics and resonant converters.

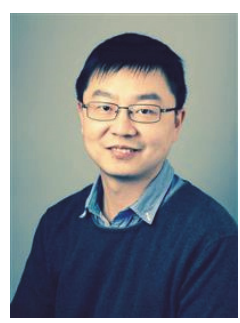

Ziwei Ouyang (S'07-M'11-SM'17) received the B.S. degree in electrical engineering from the Naval University of Engineering, Wuhan, China, in 2004, the M.S. degree from the Tianjin University of Technology, Tianjin, China, in 2007 , and the Ph.D. degree from the Technical University of Denmark (DTU), Kongens Lyngby, Denmark, in 2011.

From 2011 to 2016, he was a Post-Doctoral Researcher and an Assistant Professor with the Department of Electrical Engineering, DTU, where he is currently an Associate Professor. He has authored or co-authored over 50 peer-reviewed journals and conference publications, and holds five U.S./EP/PCT patents. His current research interests include high-frequency planar magnetic modeling and integration, high-density high-efficiency power converters, PV battery energy-storage systems, and wireless charging.

Dr. Ouyang received the Young Engineer Award at PCIM Asia 2014 and best paper awards at ECCE Asia conferences in 2010 and 2012 respectively.

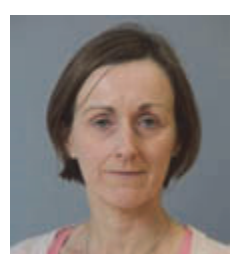

Maeve Catherine Duffy (SM'09) received the Graduation and Ph.D. degrees in electronic engineering from the National University of Ireland (NUI), Galway, Ireland, in 1992 and 1997, respectively.

From 1997 to 2001 , she was a Research Assistant with PEI Technologies, NMRC (now Tyndall National Institute), Cork, Ireland, where she worked on several European and industry funded projects focused on planar magnetics for power electronic applications. Since then, she has been a Lecturer in electrical and electronic engineering, $\mathrm{NUI}$, and she carries out her research at the Power Electronics Research Centre. She has published more than 70 peer-reviewed journal and conference papers in the areas of magnetic component design and power electronics. Her current research interests include magnetic component modeling and design for microprocessor loads, energy harvesting, and wireless power systems.

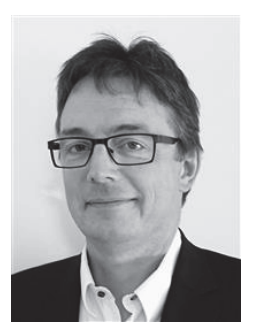

Michael A. E. Andersen (M'88) received the M.Sc.E.E. and Ph.D. degrees in power electronics from the Technical University of Denmark, Kongens Lyngby, Denmark, in 1987 and 1990 , respectively.

$\mathrm{He}$ is currently a Professor of power electronics with the Technical University of Denmark, where since 2009, he has been the Deputy Head of the Department of Electrical Engineering. His research interests include switch-mode power supplies, piezoelectric transformers, power factor correction, very high frequency power converters, and switch-mode audio power amplifiers. He is the author or co-author of more than 300 publications.

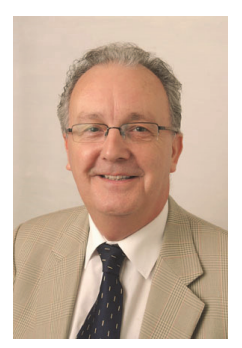

William Gerard Hurley (M'77-SM'90-F'07) received the B.E. degree in Electrical Engineering from the National University of Ireland, Cork in 1974, the M.S. degree in from the Massachusetts Institute of Technology, Cambridge MA, in 1976, the $\mathrm{PhD}$ degree at the National University of Ireland, Galway in 1988 and the higher doctorate D.Eng. degree based on his publications in 2010 .

He worked for Honeywell Controls in Canada from 1977 to 1979 and for Ontario Hydro from 1979 to 1983 . He lectured at the University of Limerick, Ireland from 1983 to 1991 and is currently professor of Electrical Engineering at the National University of Ireland, Galway. He served on the faculty at the Massachusetts Institute of Technology as a Visiting Professor in 1997/1998.

Research interests include high frequency magnetics, wireless power, and renewable energy systems. Prof. Hurley was General Chair of the Power Electronics Specialists Conference in 2000. He has co-authored a text book on transformer and inductors that has been translated into Chinese. He is the 2013 recipient of the IEEE PELS Middlebrook Award for Technical Achievement. He was appointed Distinguished Lecturer of the IEEE for 2014/17. 